\title{
Optimal Covid-19 Based PD/PID Cascaded Tracking Control for Robot Arm driven by BLDC Motor
}

\author{
MOHAMED A. SHAMSELDIN \\ Mechanical Department \\ Future University in Egypt, Cairo, EGYPT
}

\begin{abstract}
This paper presents an efficient covid-19 optimization algorithm to find the optimal values of the PD/PID cascaded controller. The purpose of the control algorithm is to force the link shaft to follow the desired reference position with good accuracy all time. This objective should be achieved for different position/time tracks regardless of load disturbance and parameter variations. This work, simulating how the covid-19 spreads and infects to optimize the parameters of the PD/ PID control. The initial values of PD/PID controller parameters consider the zero patient, which infects new patients (other values of PD/PID controller parameters). The optimization model simulates as accurately as possible the covid-19 activity. The covid-19 has two major advantages compared to other similar strategies. First, the covid-19 parameters are already adjusted according to disease statistics to prevent designers from initializing them with arbitrary values. Second, the approach has the ability to finish after several iterations where the infected population initially grows at an exponential rate. However, after some iterations. The proposed covid-19 was investigated with well-known optimization techniques such as the genetic algorithm (GA) and Harmony Search (HS) optimization. A multi-objective function is used to allow the designer to select the desired rise time, the desired settling time, the desired overshoot, and the desired steady-state error. Several tests have been performed to investigate the obtained proper values of PD/PID controller parameters. In the first test, a step position reference had been applied. In the second test, the continuous change in position reference had been subjected to the robot arm. The results provide that the covid-19 based PD/PID controller has the best performance among other techniques. In addition, the covid-19 based PID controller can track accurately the position command compared to other techniques.
\end{abstract}

Key-Words: - BLDC Motor; Covid-19 Optimization; Genetic Algorithm (GA); Harmony Search (HS); PID.

Received: February 15, 2021. Revised: July 13, 2021. Accepted: July 28, 2021. Published: August 2, 2021.

\section{Introduction}

BLDC motors are a category of permanent magnet synchronous motors [1]. They are powered by DC voltage, but current commutation is accomplished by solid-state switches [2]. The commutation instant is calculated by the rotor position which is sensed either by position sensors or by sensorless techniques [3]. BLDC motors have many excellent characteristics such as long-running life, fast dynamic behavior, satisfying productivity, linear speed vs. Torque characteristics, and higher torqueweight ratio [4]. Therefore, the BLDC motor has been used in several applications such as electric automotive, robotics, and CD-ROMS in such applications BLDC motor is subjected to many kinds of load disturbances [5].

Robotic systems are extensively applied in several fields of engineering such as the medical industry, space and process industry for position tracking, accurate positioning, nuclear plant, pick and place, etc. The effective movement of a manipulator can be accomplished only with tight position control [6].
The PID controller has been widely utilized because of its simplicity, ease of implementation, and costeffectiveness [7]. However, control of higher-order, nonlinear, time-delayed, and complex indefinite systems is beyond the abilities of the PID controller [8]. Besides, the system backlash and friction make the task of the controller is significantly hard [9]. Moreover, the nonlinearity of the six-step inverter causes intermittent rotor speed if the robot arm is actuated by the BLDC motor [10].

This problem can be alleviated by implementing advanced control algorithms such as adaptive control, variable structure control, fuzzy control, and neural network [11]. The variable structure controller is simple, but it is difficult to perform practically [12]. This is because of the possibility of an unexpected change in the control signal, which might affect the system operation [13]. A neuralnetwork-based motor control system presents an optimal solution to deal with the system uncertainty and the disruption of the system, whereas it needs more computing capacity and data storage space [14]. Fuzzy control theory usually provides non- 
linear controllers that can implement a complex non-linear control action even for uncertain nonlinear systems [15]. A fuzzy-logic control system based on the expert knowledge database needs fewer calculations, but it lacks sufficient capacity for the new rules [16].

The challenge of a conventional PID controller is the selection of the proper parameters for a certain application [17]. There are several techniques to find the PID controller parameters such as try and error and Ziegler and Nichols methods [18]. However, these previous techniques give an approximate solution [7]. Recently, optimization techniques can be used to find the optimal values of the PID controller parameters. There are different types of optimization techniques such as Genetic Algorithm (GA) which is employed successfully to solve complex optimization problems, Particle Swarm Optimization (PSO), ant colony optimization, and Harmony Search (HS) optimization.

The COVID-19 considers an unknown respiratory virus, lately revealed in humans in December 2019, that has spread worldwide where more than 10 million infected people so far. This virus can infect people and these people can either die, infect other people, or just get recovered after the infection [19]. Vaccines and the immune defense system usually fight the disease and aid to alleviate its effects while an individual is still infected. This behavior can be modeled by a SIR model, consisting of three categories of individuals: $\mathrm{S}$ presents the number of susceptible, I stands for the number of infectious, and $\mathrm{R}$ is the number of recovered. Metaheuristics need to deal with huge search spaces, even infinite for the continuous cases and must find suboptimal solutions in reasonable execution times.

The fast propagation of the coronavirus along with its ability to infect most of the countries in the world impressively fast has inspired the novel metaheuristic proposed in this work, named covid19 optimization algorithm. The proposed covid-19 optimization algorithm is used to find the optimal parameters for the PID controller. The Vaccines stands for the used objective function which can treat the infected patients. The covid-19 optimization algorithm has been used to find the optimal values of the PID controller parameters based on a multi-objective function that contains the desired rise time, desired settling time, desired maximum overshoot, and desired steady-state error.

The purpose of the control system is to track accurately a preselected reference position of the robot arm driven by a BLDC motor. A Comparative study utilizing Grey Wolf Optimizer (GWO),
Particle Swarm Optimization (PSO), and Genetic Algorithms was presented in [21]. Results indicated that the suggested GWO algorithm has a lower root mean square compared to PSO and GA, and therefore, it could be an effective method for optimal PID controllers for power converters applications.

Position control of BLDC motor employing HS Algorithm optimization technique was demonstrated in [22]. It validates that the HS method can enhance the dynamic performance of the system in a better way.

The design of a PSO optimized PID controller for the process liquid level control was illustrated in [23]. The computer simulation results indicate far better settling time and peak values with PSO optimized PID control, thus ensuring overall higher efficiency.

Performance comparison of Moth-Flame Algorithm (MFO) and PSO for optimal tuning the fractional order fuzzy PID controller for A DC-DC boost converter was designed in [24]. The MFO method is helpful to select the best values of fractional order fuzzy PID Controller for a DC-DC boost converter.

The paper is prepared as following, firstly, the modeling of single degree robot arm driven by BLDC motor is presented. Secondly, the covid-19 optimization algorithm is explained. Thirdly, the proposed covid-19 based PD/PID controller is demonstrated. Fourthly, the simulation results are illustrated. Finally, the conclusion is discussed.

\section{Robot Arm Model}

This section illustrates the detailed differential equations of single-degree arm robot actuated by BLDC motor. Fig. 1 shows the overall drive system which consists of three main parts. Part one is the BLDC motor, the second one presents the gearbox and finally, the last part is the mechanical link.

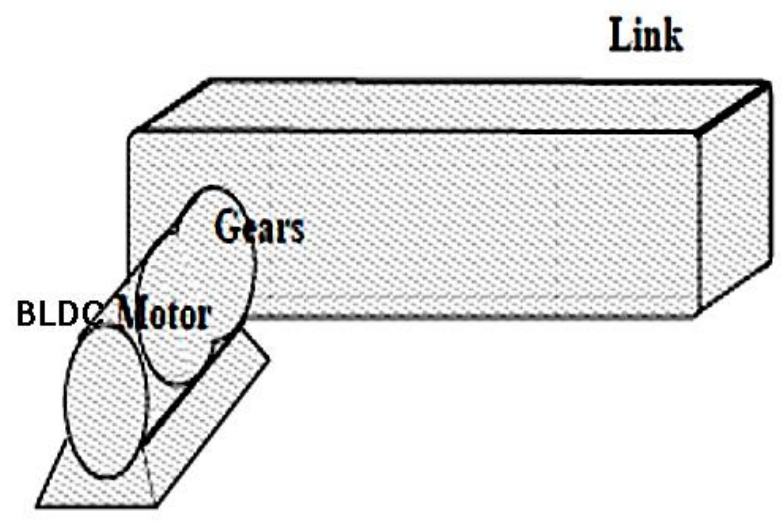

Fig. 1. Single Degree Robot Arm Driven by BLDC Motor 
Let $\theta_{l}$ and the $\theta_{m}$ denote the angles of the link and motor shaft, respectively.

Then $\theta_{m}=r \theta_{l}$ where $\mathrm{r}: 1$ is the gear ratio.

The kinetic energy $(\mathrm{K})$ of the system is given by

$$
K=\frac{1}{2} J_{m} \dot{\theta}_{m}{ }^{2}+\frac{1}{2} J_{l} \dot{\theta}_{l}{ }^{2}=\frac{1}{2}\left(r^{2} J_{m}+J_{l}\right) \dot{\theta}_{l}{ }^{2}
$$

where $J_{m}$ and $J_{l}$ are the rotational inertias of the motor and the link, respectively.

The potential energy is given as

$$
P=\operatorname{Mg} \ell\left(1-\cos \theta_{l}\right)
$$

where $M$ is the total mass of the link and $\ell$ is the distance from the joint axis to the link center of mass.

Defining $\quad J=r^{2} J_{m}+J_{l}$

The Lagrangian $L_{g}$ is given by

$$
L_{g}=K-P=\frac{1}{2} J \dot{\theta}_{l}^{2}-M g \ell\left(1-\cos \theta_{l}\right)
$$

Substituting this expression into the Euler-Lagrange equations yields the equation of motion

$$
J \ddot{\theta}_{l}+M g \ell \sin \theta_{l}=T_{L}
$$

The generalized force $T_{L}$ represents those external forces and torques.

$$
\begin{gathered}
T_{L}=u-B \dot{\theta}_{l} \\
u=r T_{m} \\
B=r B_{m}+B_{l}
\end{gathered}
$$

Where $T_{m}$ presents the torque developed by the motor, $B_{m}$ is the motor viscous damping, $B_{l}$ is the load viscous damping and $B$ is the equivalent viscous damping as seen by the motor.

Therefore the complete expression for the dynamics of this system is

$$
J \ddot{\theta}_{l}+B \dot{\theta}_{l}+M g \ell \sin \theta_{l}=u
$$

The block diagram of the drive system is shown in Fig. 2. The main components of the drive system of the BLDC motor consist of a six-step voltage source inverter, a logic circuit, and three hall effect sensors.

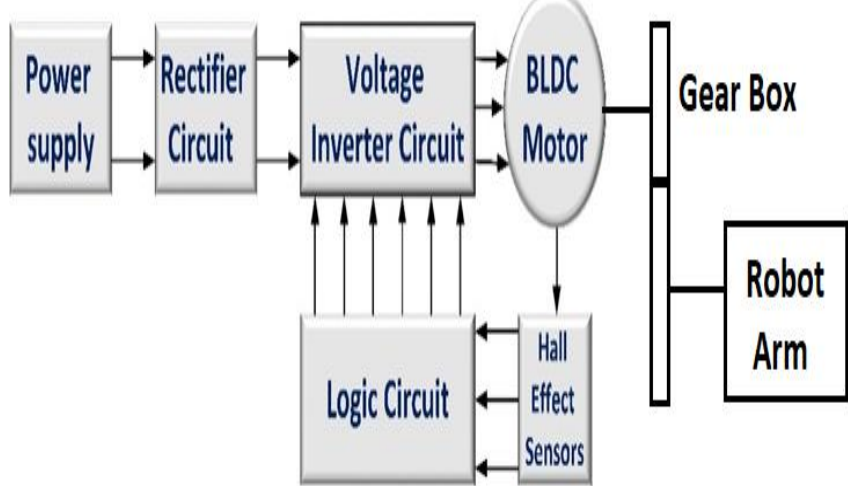

Fig. 2. The main component of the BLDC motor with a robot arm.

The model equations of a BLDC motor are composed of a voltage equation, a torque equation, and a motion equation. The stator of a general BLDC motor has three windings like an induction motor. Equations (10) through (17) represent the dynamical model of BLDC motor. These equations are based on the following:

- The stator has a Y-connected concentrated full-pitch winding.

- The inner rotor has a non-salient pole structure.

- $\quad$ Three hall sensors are placed symmetrically at $120^{\circ}$ interval.

$$
v_{a b}=R\left(i_{a}-i_{b}\right)+(L-M) \frac{d}{d t}\left(i_{a}-i_{b}\right)+e_{a}-e_{b}
$$

$v_{b c}=R\left(i_{b}-i_{c}\right)+(L-M) \frac{d}{d t}\left(i_{b}-i_{c}\right)+e_{b}-e_{c}$

$$
\begin{gathered}
v_{c a}=R\left(i_{c}-i_{a}\right)+(L-M) \frac{d}{d t}\left(i_{c}-i_{a}\right)+e_{c}-e_{a} \\
e_{a}=\frac{K_{e}}{2} w_{m} F\left(\theta_{e}\right) \\
e_{b}=\frac{K_{e}}{2} w_{m} F\left(\theta_{e}-\frac{2 \pi}{3}\right) \\
\mathrm{e}_{\mathrm{c}}=\frac{\mathrm{K}_{\mathrm{e}}}{2} \mathrm{w}_{\mathrm{m}} \mathrm{F}\left(\theta_{\mathrm{e}}-\frac{4 \pi}{3}\right)
\end{gathered}
$$

$$
T_{m}=\frac{K_{t}}{2}\left[F\left(\theta_{e}\right) i_{a}+F\left(\theta_{e}-\frac{2 \pi}{3}\right) i_{b}+F\left(\theta_{e}-\frac{4 \pi}{3}\right) i_{c}\right]
$$

$$
\begin{gathered}
F\left(\theta_{e}\right)= \\
\left\{\begin{array}{cc}
1 & 0 \leq \theta_{e} \leq \frac{2 \pi}{3} \\
1-\frac{6}{\pi}\left(\theta_{e}-\frac{2 \pi}{3}\right) & \frac{2 \pi}{3} \leq \theta_{e} \leq \pi \\
-1 & \pi \leq \theta_{e} \leq \frac{5 \pi}{3} \\
-1+\frac{6}{\pi}\left(\theta_{e}-\frac{5 \pi}{3}\right) & \frac{5 \pi}{3} \leq \theta_{e} \leq 2 \pi
\end{array}\right\}
\end{gathered}
$$


Where $K_{e}$ is the line back-emf constant, $K_{t}$ presents the line torque constant, $e_{a}, e_{b}, e_{c}$ are the phase back emf's, $i_{a}, i_{b}, i_{c}$ are the phase current, $v_{a b}, v_{b c}, v_{c a}$ are the line-to-line voltages, $\theta_{e}$ is the electrical angle $\left(\theta_{e}=\frac{P}{2} \theta_{m}\right), \omega_{m}$ is the rotor speed, $L$ is the phase inductance, $P$ is the number of pole pairs and $R$ is the DC resistance.

From Equations (7), (9) and (16) can obtain the equation (18).

$$
\begin{aligned}
& J \ddot{\theta}_{l}+B \dot{\theta}_{l}+M g \ell \sin \theta_{l}=\frac{r K_{t}}{2}\left[F\left(\theta_{e}\right) i_{a}+\right. \\
& \left.F\left(\theta_{e}-\frac{2 \pi}{3}\right) i_{b}+F\left(\theta_{e}-\frac{4 \pi}{3}\right) i_{c}\right]
\end{aligned}
$$

Fig. 3 shows the Simulink model of the single-degree robot arm actuated by BLDC motor. The input for the open-loop system is the DC voltage of the motor and the output of the system is the position of the robot arm.

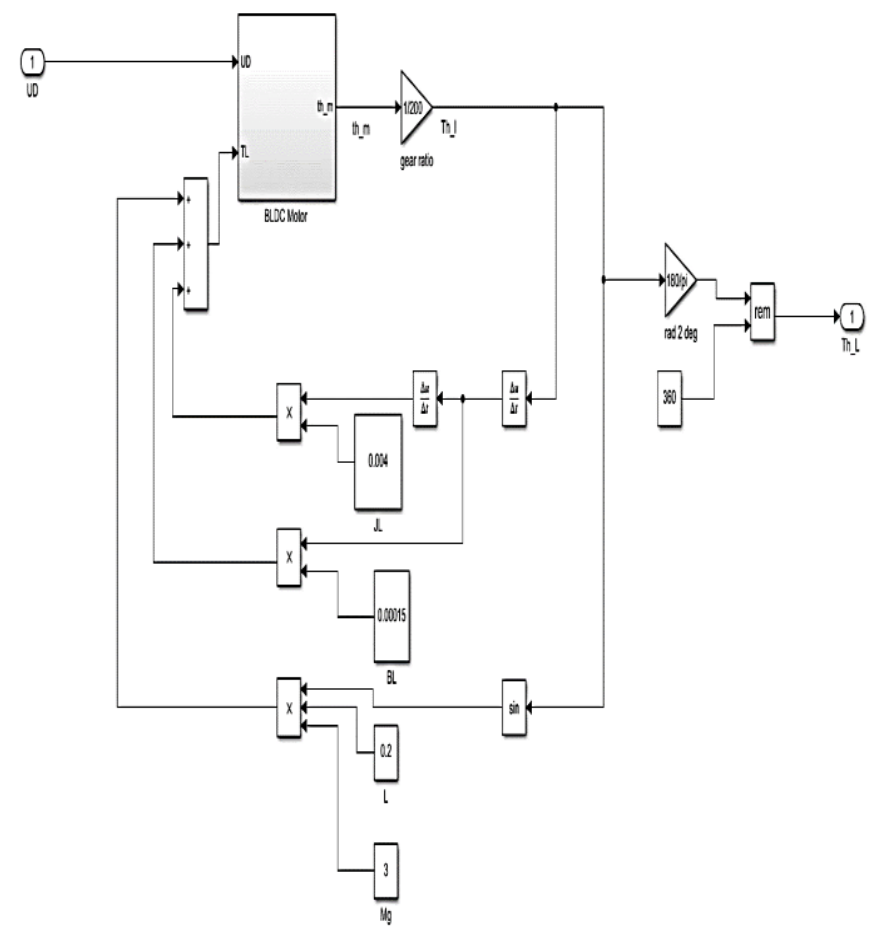

Fig. 3. The SIMULINK model of the BLDC motor with a robot arm.

Table 1 shows the system parameters of the robot arm driven by the BLDC motor.

\begin{tabular}{|c|c|c|c|}
\hline Name & Symbol & Value & Units \\
\hline DC resistance & $R$ & 0.57 & $\Omega$ \\
\hline Inductance & $L$ & 1.5 & $\mathrm{mH}$ \\
\hline $\begin{array}{l}\text { Torque } \\
\text { constant }\end{array}$ & $K_{t}$ & 0.082 & N.m/A \\
\hline No. of Poles & $P$ & 4 & \\
\hline Rated torque & $T_{p}$ & 0.62 & N.m \\
\hline $\begin{array}{l}\text { Rated } \\
\text { Voltage }\end{array}$ & V & 36 & V \\
\hline Rotor Inertia & $J_{m}$ & $23 e^{-6}$ & Kg.m ${ }^{2}$ \\
\hline $\begin{array}{l}\text { viscous } \\
\text { damping }\end{array}$ & $B_{m}$ & 0.0000735 & \\
\hline Rated Speed & $\omega$ & 4000 & RPM \\
\hline Rated current & $I$ & 5 & A \\
\hline \multicolumn{4}{|c|}{ Mechanical system parameters } \\
\hline Link mass & $M$ & 0.3 & $\mathrm{~kg}$ \\
\hline Link inertia & $J_{l}$ & 0.004 & Kg.m ${ }^{2}$ \\
\hline $\begin{array}{l}\text { Link viscous } \\
\text { damping }\end{array}$ & $B_{l}$ & 0.00015 & N.M.S \\
\hline Link length & $\ell$ & 0.2 & $\mathrm{~m}$ \\
\hline Gear ratio & $r$ & 50 & \\
\hline
\end{tabular}

Table 1. System parameters

Fig. 4 illustrates the open-loop position cycle of the robot arm at the rated voltage ( $36 \mathrm{~V}$ ) of the BLDC motor. It can note that the cycle has a period of 3 seconds to complete one revolution. At the time from 2 seconds to 3 seconds, the arm rotates quickly from 150 degrees to 360 degrees because of the arm's inertia.

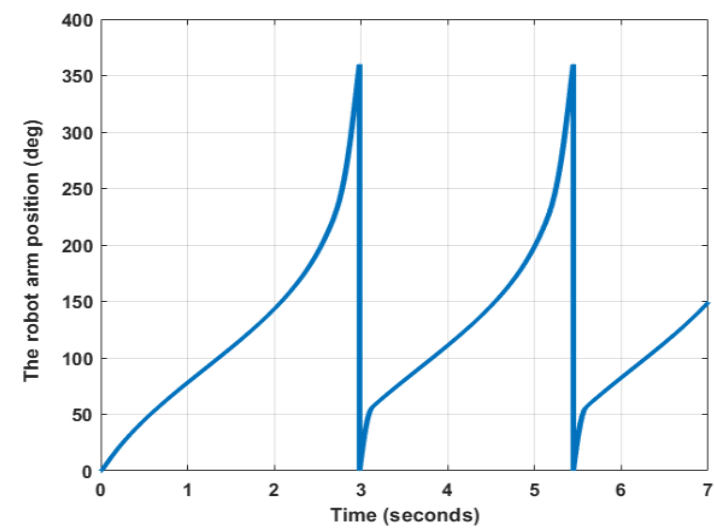

Fig. 4. The robot arm position cycle at rated voltage.

Fig. 5 shows the corresponding rotational speed of the robot arm. It is obvious that the rotational speed increases slowly in the period from 0 seconds to 2 seconds while it increases suddenly to a negative value because of the inertia effect. Also, Fig. 6 demonstrates the corresponding DC current of the BLDC motor through the robot arm rotation. 


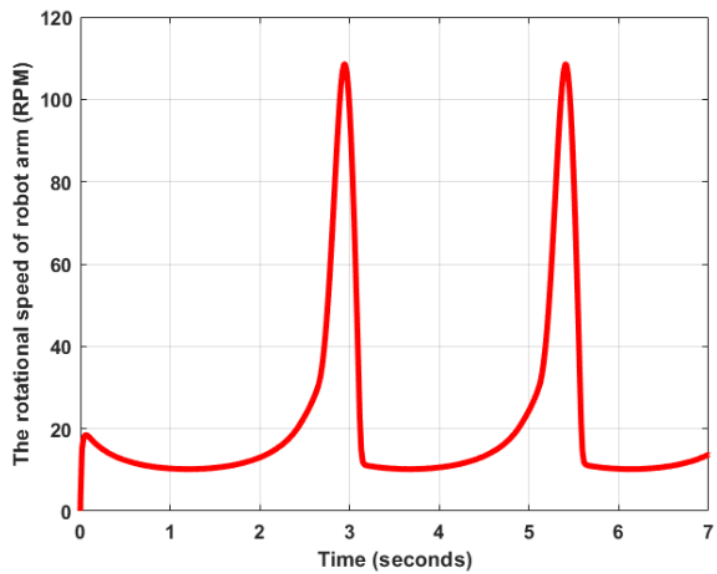

Fig. 5. The corresponding rotational speed of the robot arm at rated voltage.

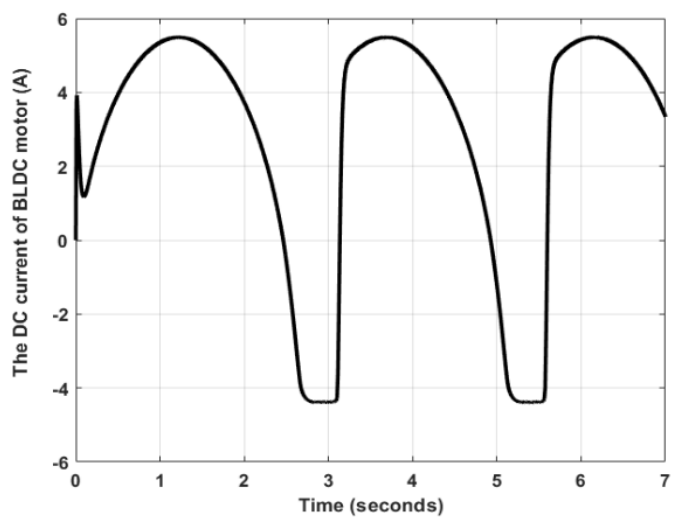

Fig. 6. The corresponding DC current of motor winding.

\section{Covid-19 Based PD/PID Controller}

\subsection{Covid-19 Optimization Algorithm}

There are several bioinspired metaheuristics to deal with optimization problems. Although Covid 19 has been considered to optimize any type of optimization problem, this section focused on optimization algorithms used to find the optimal value of the PD/PID controller parameters. The first step, generation of the initial population. The initial population (zero patient) contains one individual vector. As in the coronavirus epidemic scenario, it recognizes the first human being infected.

In the second step, the disease spread depends on the behavior of one individual vector (zero patient), several cases can be considered. The first case is some of the infected individuals die. The possibility of death is according to the coronavirus death rate. Such individuals can no longer infect new individuals. The second case is the individuals surviving the coronavirus will infect new individuals (intensification). Therefore, two types of disease propagation are taken into account, according to a given probability. For ordinary spreaders. Infected individuals will infect new ones according to the rate of spreading rate while if the coronavirus spreading is high, the infected individuals will infect new ones according to the coronavirus super spreading rate. Both ordinary and super-spreaders individuals can follow and find solutions quite dissimilarly. Therefore, individuals have a probability of traveling thus allowing them to spread the disease to solutions that may be quite different.

The third step, modernizing populations. Three populations are preserved and updated for each generation. Dead population. If any individual dies, it is added to this population and can never be used again. Recovered population. After each iteration, infected individuals (after spreading the coronavirus according to the previous step) are sent to the recovered population. It is known that there is a reinfection probability. Hence, an individual fitting to this population could be re-infected at any iteration provided that it matches the reinfection criterion.

Another condition must be measured since individuals can be isolated simulating they are executing the social distancing procedures. For easiness, it is considered that an isolated individual is sent to the recovered population as well when meeting an isolation probability.

Recently, a newly infected population. This population collects all individuals infected at each iteration, according to the procedure described in the previous steps. It is possible that repeated new infected individuals are created at each iteration and, consequently,

It is recommended to eliminate such repeated individuals from this population before the next iteration starts running. The Vaccines considers the used objective function, which can treat the infected population.

The fourth step, Stop criterion. One of the most important features of the proposed algorithm lies in its capability to end without the need of controlling any parameter. This situation occurs because the recovered and dead populations are constantly increasing as time goes by, and the newly infected population cannot infect new individuals. It is estimated that the number of infected individuals increases for a certain number of iterations. However, from a particular iteration on, the size of the newly infected population will be smaller than that of the current one because recovered and dead populations are too big, and the size of the infected population decays over time.

\subsection{Covid-19 Based PD/PID Controller}

The conventional PID controller is executed in various fields of engineering applications owing to its simplicity, reliability, and flexibility of tuning its parameters. The transfer function of the PID controller is $K(s)=K_{P}+\frac{K_{I}}{s}+K_{D} s$. Where $K_{P}, K_{I} \quad$ and $k_{D} \quad$ are proportional, integral, and differential gains respectively. The function of each part of a PID controller can be described as follows, the proportional part decreases the error responses of the system to disturbances, the integral part rejects the steady-state error, and finally, the 
derivative part diminishes the dynamic response and improves the system stability.

The challenge in the PID controller is to choose the three parameters to be suitable for the controlled plant. There are many methods to define the parameters of PID controller such as try and error and Ziegler-Nichols methods but most of these methods are rough roads. Therefore, this paper presents a new covid 19 optimization methodology to find the optimal values of the PID controller.

The initial population contains the upper and lower values of the PD/PID cascaded controller parameters as shown in the equations from (3) to (5).

$$
\begin{gathered}
X=\left[\begin{array}{ccccc}
K_{P 0}^{\prime} & K_{D 0}^{\prime} & K_{P 0} & K_{I 0} & K_{D 0} \\
\cdot & \cdot & \cdot & \cdot & \cdot \\
\cdot & \cdot & \cdot & \cdot & \cdot \\
\cdot & \cdot & \cdot & \cdot & \cdot \\
K_{P n}^{\prime} & K_{D n}^{\prime} & K_{P n} & K_{I n} & K_{D n}
\end{array}\right] \\
L_{X}=\left[\begin{array}{lllll}
K_{P 0}^{\prime} & K_{D 0}^{\prime} & K_{P 0} & K_{I 0} & K_{D 0}
\end{array}\right] \\
U_{X}=\left[\begin{array}{lllll}
K_{P n}^{\prime} & K_{D n}^{\prime} & K_{P n} & K_{I n} & K_{D n}
\end{array}\right]
\end{gathered}
$$

The performance of each row will be investigated according to the objective function in equation (6). The poor performance specifies the infected population, which has the possibility to die. While the good performance indicates the recovered population from corona antivirus.

$$
\begin{gathered}
J_{t}=\left(J_{1}+J_{2}+J_{3}+J_{4}\right) / 4 \\
J_{1}=\frac{\left|t_{r}-t_{r d}\right|}{t_{r d}} \\
J_{2}=\frac{\left|t_{s}-t_{s d}\right|}{t_{s d}} \\
J_{3}=\frac{\left|e_{s s}-e_{s s d}\right|}{e_{s s d}} \\
J_{4}=\frac{\left|O S-o s_{d}\right|}{o s_{d}}
\end{gathered}
$$

Where $\left(t_{r d}\right)$ is the desired rise time and $\left(t_{r}\right)$ is the measured rise time, $\left(O S_{d}\right)$ is the desired maximum overshoot and $(O S)$ is the actual overshoot, $\left(t_{s d}\right)$ is the desired settling time and $\left(t_{s}\right)$ is the determining settling time, and $\left(e_{s s d}\right)$ is the desired steady-state error and $\left(e_{s s}\right)$ is the estimated steady-state error.

It can be noted that objective function attempts to satisfy the designer using four sub-objective functions. The first sub-objective function focuses on improving the rise time of overall drive systems. The second subobjective function attempts to reduce the settling time. The third sub-objective function measures the steadystate error. The fourth sub-objective function investigates the required overshoot.
The value of each sub-objective function ranges from zero to one. So, the overall objective function considers the average of the sum of four sub-objective functions. Fig. 7 shows the covid-19 offline tuning system with the robot arm driven by a BLDC motor.

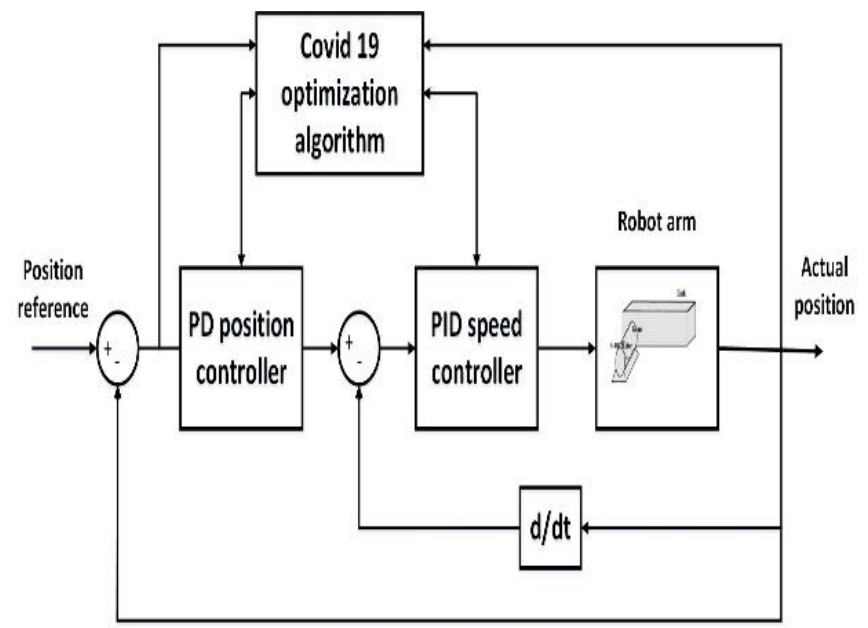

Fig. 7. The Covid-19 tuning system with robot arm driven by BLDC motor.

The sequence flow chart of optimization is shown in Fig. 8. The first step investigates the Probability of travel If $P_{t}=0$ then the type of spreading is $S_{R}=(0$ to 0.5$)$. In case of $P_{t}=1$ then the type of spreading $S_{R R}=$ (0.5 to 1). The second step, the zero infected patient If $P_{t}=0$ will become as follows.

$$
X_{F 0}=L_{X}+\left(U_{X}-L_{X}\right) S_{R}
$$

If zero infected patient If $P_{t}=1$

$$
X_{F 0}=L_{X}+\left(U_{X}-L_{X}\right) S_{R R}
$$

The third step investigates if $J_{t}>P_{D I E}$ then this patient is dead and generates a newly infected patient. In case of $J_{t}<P_{D I E}$ then the newly infected patient will be as follows.

$X_{\text {new }}=X_{\text {old }} \pm X_{\text {old }}\left[\begin{array}{c}J_{1} D_{R} \\ \left(0.5 J_{2}+0.5 J_{3}\right) D_{R} \\ J_{4} D_{R}\end{array}\right]$

The optimization will be stopped if $\left(X_{\text {new }}=X_{\text {old }}\right)$ where the newly infected populations cannot infect new individuals. If the number of iteration ended before this previous condition. the covid 19 optimization algorithm cannot give the optimal solution. Therefore, to obtain the optimal parameters of PD/PID controller must be $X_{\text {new }}=X_{\text {old }}$ to guarantee the global solution.

Table 2 demonstrates the used covid-19 optimization algorithm parameters through offline optimization. 
Table 2. The covid 19 optimization algorithm parameters

\begin{tabular}{|c|c|c|c|}
\hline No & $\begin{array}{c}\text { CVOA } \\
\text { Parameter }\end{array}$ & Symbol & Value \\
\hline 1 & $\begin{array}{c}\text { Probability of } \\
\text { Death }\end{array}$ & $P_{D I E}$ & $\begin{array}{l}\text { random value from } 0 \\
\text { to } 1\end{array}$ \\
\hline 2 & Death Rate & $D_{R}$ & $\begin{array}{l}\text { random value from } 0 \\
\text { to } 1\end{array}$ \\
\hline 3 & $\begin{array}{l}\text { Spreading } \\
\text { Rate }\end{array}$ & $S_{R}$ & $\begin{array}{c}\text { random value from } 0 \\
\text { to } 0.5\end{array}$ \\
\hline 4 & $\begin{array}{c}\text { Super } \\
\text { Spreading } \\
\text { Rate }\end{array}$ & $S_{R R}$ & $\begin{array}{c}\text { random value from } 0.5 \\
\text { to } 1\end{array}$ \\
\hline 5 & $\begin{array}{c}\text { Probability of } \\
\text { travel }\end{array}$ & $P_{t}$ & $\begin{array}{c}\text { random binary value } 0 \\
\text { or } 1\end{array}$ \\
\hline
\end{tabular}

The objective function has been minimized subjected to:

$$
\begin{gathered}
K_{P \min } \leq K_{P} \leq K_{P \max } \\
K_{I \min } \leq K_{I} \leq K_{I \max } \\
K_{D \min } \leq K_{D} \leq K_{D \max }
\end{gathered}
$$

The upper and lower limits of PID controller parameters as the following.

$$
\begin{aligned}
L_{X} & =\left[\begin{array}{lll}
K_{P \min } & K_{I \min } & K_{D \min }
\end{array}\right] \\
U_{X} & =\left[\begin{array}{lll}
K_{P \max } & K_{I \max } & K_{D \max }
\end{array}\right]
\end{aligned}
$$

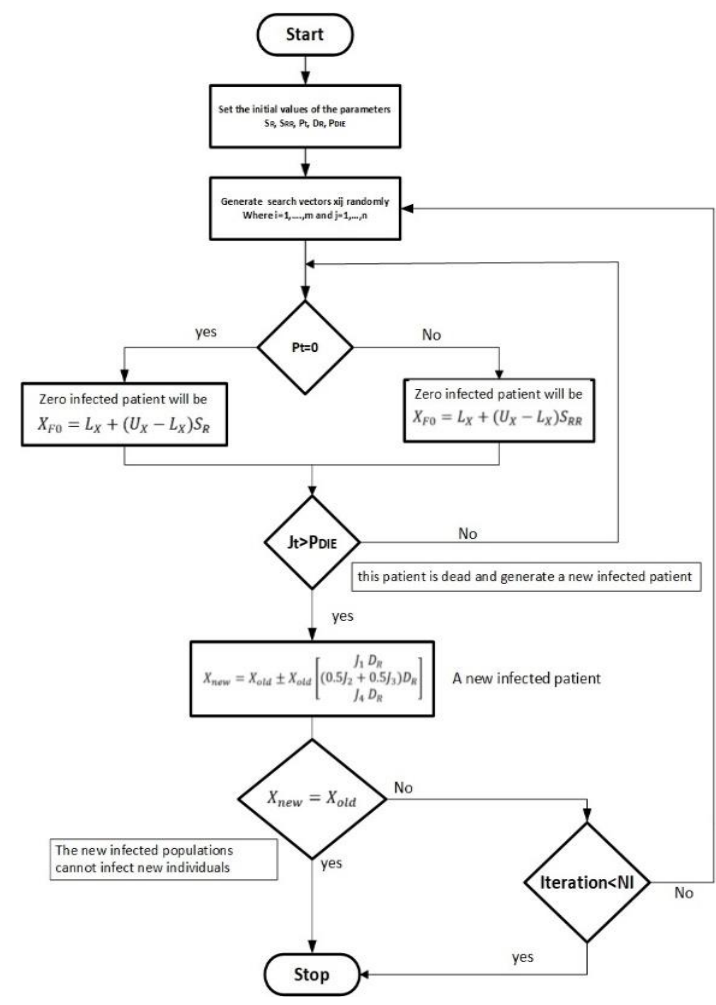

Fig. 8. The covid-19 optimization algorithm flow chart.
Best Fitness values are plotted against generations or number of iterations to get the convergence characteristic shown in Fig. 9.

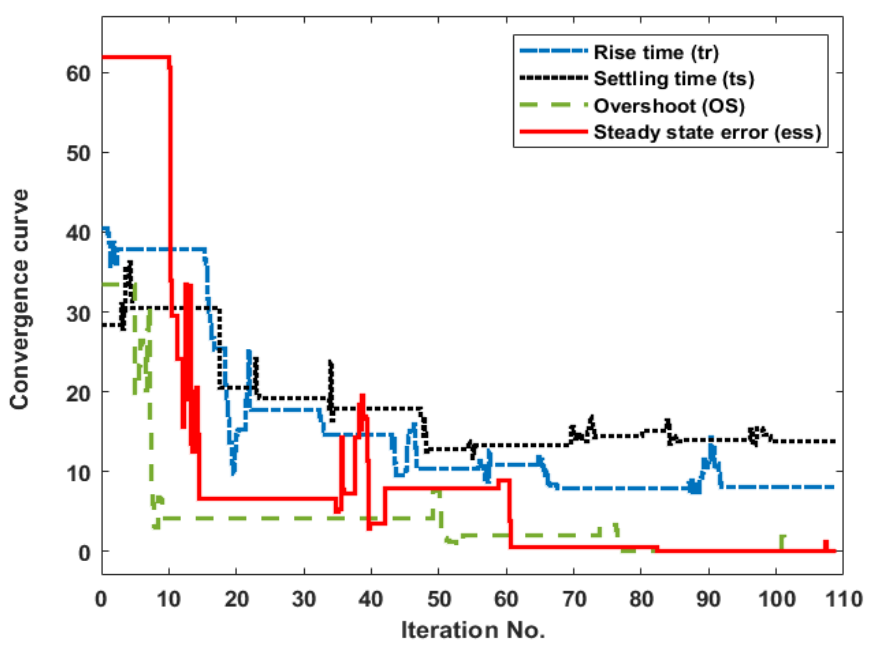

Fig. 9. The convergence curve for GA, HS, and Covid19.

Fig. 10 illustrates the convergence curve of the objective function through the covid-19 optimization tuning.

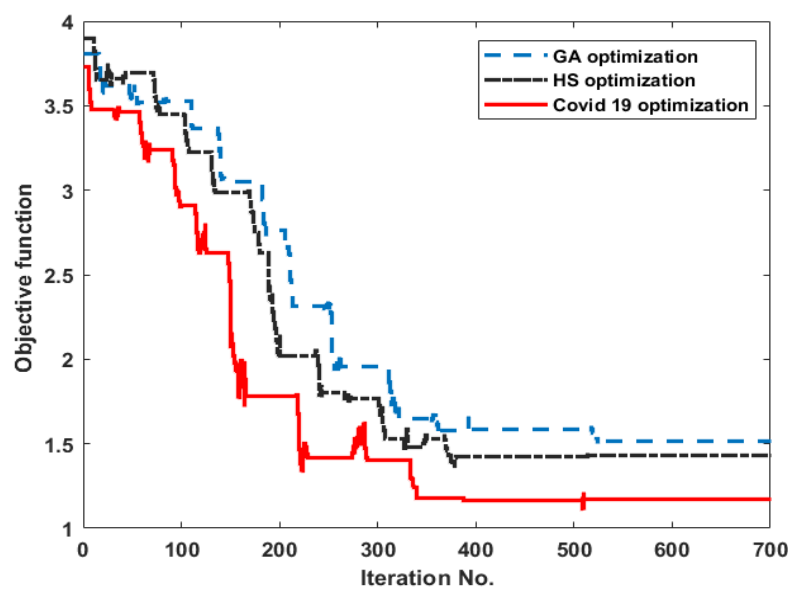

Fig. 10. The objective function performance for Covid-19 optimization.

Table 3 shows the obtained values of PD/PID controller parameters using several optimization techniques (GA optimization, HS optimization, and the proposed covid-19 optimization).

Table 3. The covid 19 optimization algorithm parameters.

\begin{tabular}{cccccc}
\hline $\begin{array}{c}\text { Controller } \\
\text { method }\end{array}$ & $K_{P}^{\prime}$ & $K_{D}^{\prime}$ & $K_{P}$ & $K_{I}$ & $K_{D}$ \\
\hline $\begin{array}{c}\text { GA Algorithms } \\
\text { HS }\end{array}$ & 0.5 & 0.13 & 8.35 & 10.025 & 0.1 \\
$\begin{array}{c}\text { optimization } \\
\text { Covid 19 }\end{array}$ & 2 & 1.1 & 5.58 & 20.214 & 0.02 \\
optimization & 4.25 & 0.12 & 7.65 & 21.56 & 0.05 \\
\hline
\end{tabular}




\section{Simulation Results}

This section demonstrates the performance of tracking control for three types of PD/PID controllers. The first type has been implemented based on the GA optimization technique. The second type is designed using the HS algorithm. The third type was developed by a new covid19 optimization approach.

\subsection{Step position reference}

Fig.11 shows a comparison between the proposed covid-19 based PD/PID controller and other techniques (GA and HS) at step position test for the robot arm. The comparison displays the covid 19-PD/PID controller can absorb the nonlinearity of power inverter and mechanical uncertainty. Therefore, it gives the best performance compared to other techniques. The rise and settling times are small and zero overshoot.

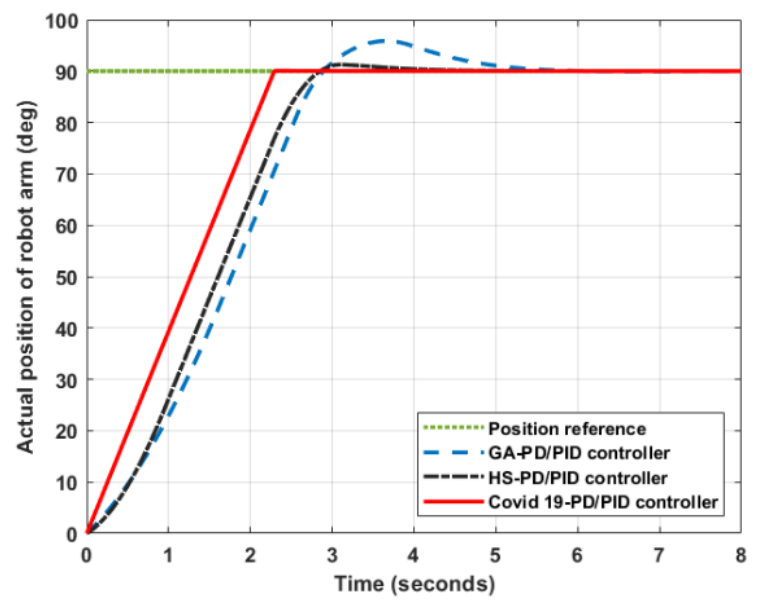

Fig. 11. The robot arm position response at step reference.

Fig. 12 shows the PD/PID controller output for each algorithm. It can be noted that the covid-19 PD/PID controller has the fastest response among other techniques. In addition, it can reach a zero value suddenly at the required position of the robot arm.

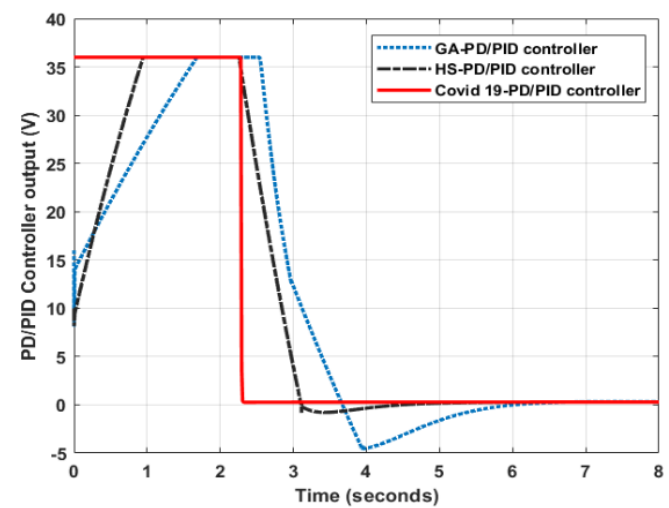

Fig. 12. The output of each controller at step position command.
Fig. 13 demonstrates the robot arm speed at each $\mathrm{PD} / \mathrm{PID}$ controller type. It is obvious that the covid-19 $\mathrm{PD} / \mathrm{PID}$ controller can acquire the required speed at a short time compared to other PD/PID controllers (GA and HS). The GA PD/PID and HS PD/PID controllers have low dynamic speed responses through the test.

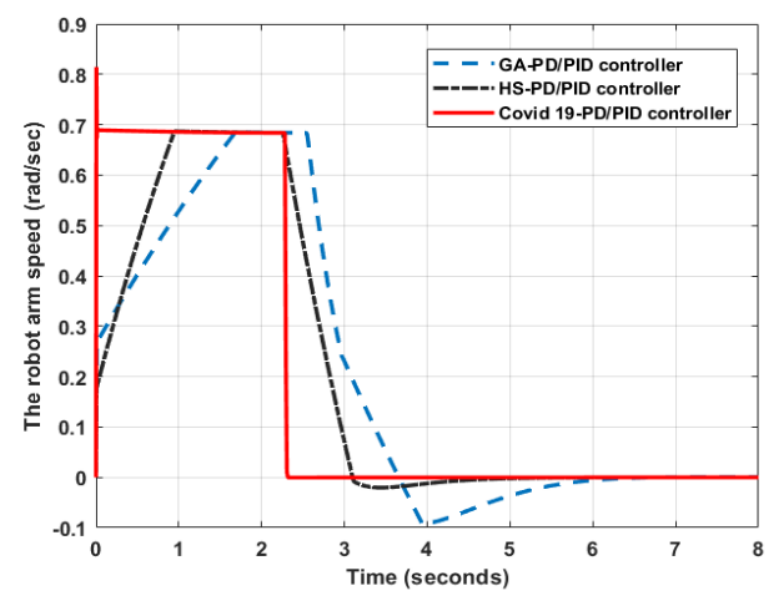

Fig. 14. The load torque of robot arm of control techniques at step position command.

Fig. 15 demonstrates the corresponding DC current of the motor rotor winding through the step reference test. It is obvious that the covid-19 PD/PID controller has a high current from zero to 2 seconds approximately. Then, the rotor current steadies at $0.58 \mathrm{~A}$ until the completion of simulation time. A high current under-shoot occurred when the robot arm reaches the required position to correspond to the under-shoot in the load torque.

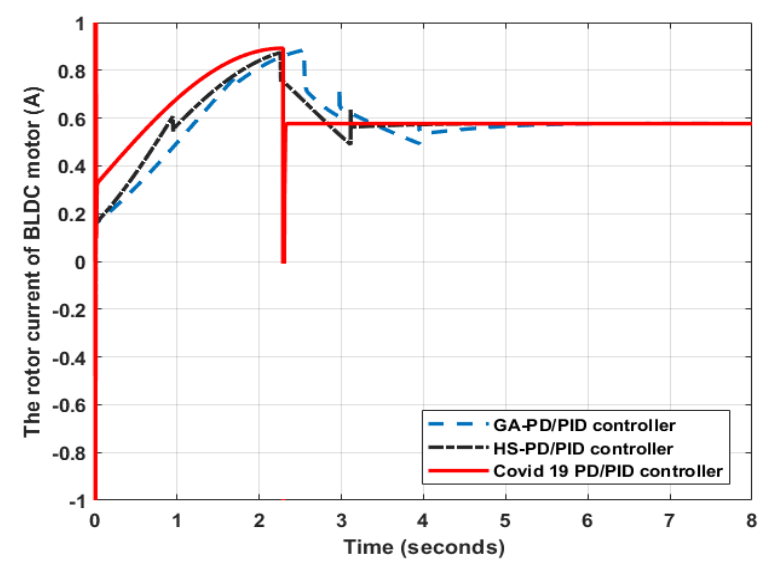

Fig. 15. The rotor current of BLDC motor of control techniques at step position command.

\subsection{Variable position reference}

Fig.16 illustrates the performance of the proposed controllers under several position commands. It can be noted that the covid-19 based PD/PID controller can track accurately the preselected position profile although the inverter voltage switching and nonlinear dynamics of the robot. The GA-based PD/PID controller has a high overshoot at each new command and a high settling time. The HS-based PD/PID controller gives an average performance compared to other control techniques. 


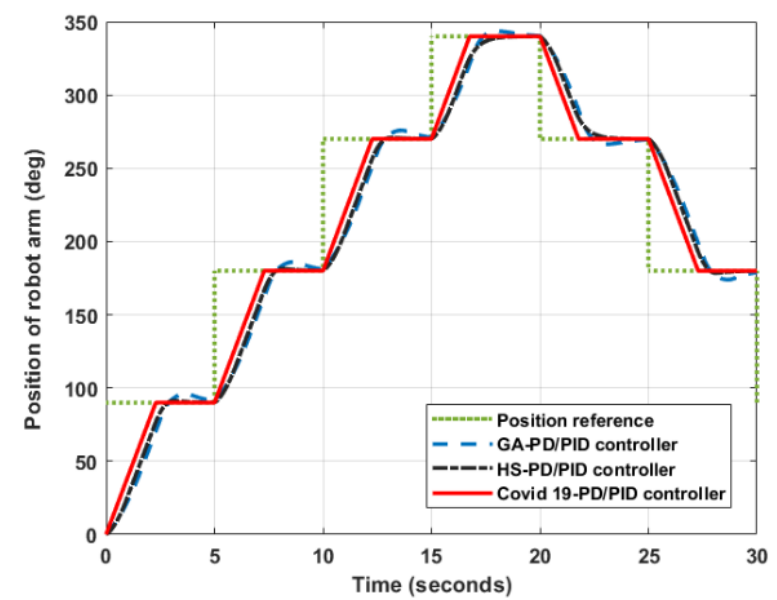

Fig. 16. The position of the robot arm at different commands.

Fig. 17 demonstrates the corresponding PD/PID controller output for each control technique. It is obvious that the covid-19 PD/PID controller output has a sharp change at every new position command. The polarity of controllers' output will be reversed due to the change of position command from high value to low value. In addition, the controller output fluctuates between the \pm 36 volts (rated voltage) because of the continuous change in position commands.

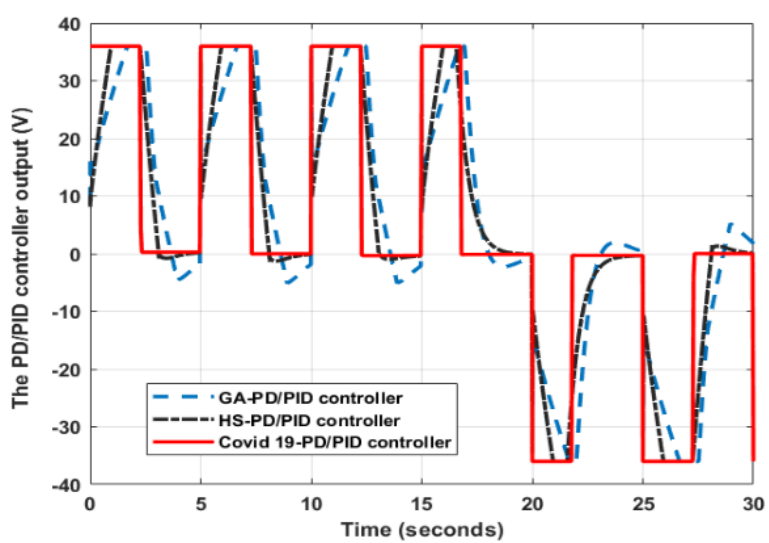

Fig. 17. The output of each controller at variable position command.

Fig. 18 exhibits the corresponding robot arm speed of several types of PD/PID controllers during the tracking test. It is obvious that the covid-19 PD/PID controller can reach the suitable speed at a minor time while the other $\mathrm{PD} / \mathrm{PID}$ controllers (GA and HS) have a ramp speed response through the test.

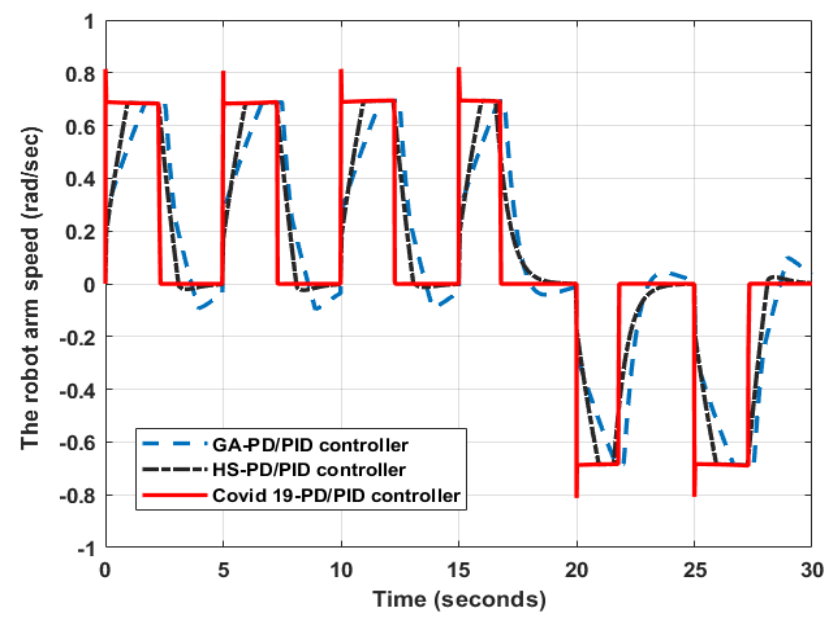

Fig. 18. The robot arm speed of each controller at variable position command.

Fig. 19 shows the load torque of the robot arm through the variable position command. It is clear that the robot arm in the case of the covid-19 PD/PID controller can track the required value of torque to achieve high resolution and satisfying dynamics. In addition, there is a shutter in torque due to the sudden change in position command. Moreover, The GA-based PD/PID and HSbased PD/PID controller have a delay in the required torque.

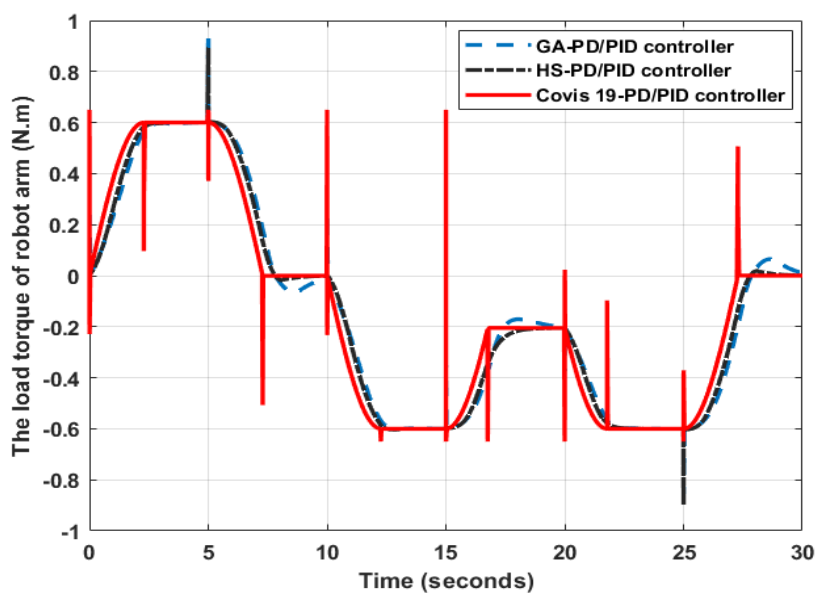

Fig. 19. The load torque of robot arm at variable position command.

Fig. 20 demonstrates the matching DC current of the motor through the variable position commands test. It is clear that the covid-19 based PD/PID controller can generate a suitable current to achieve high position accuracy. In addition, there is a shuttering in current at each new position command. 


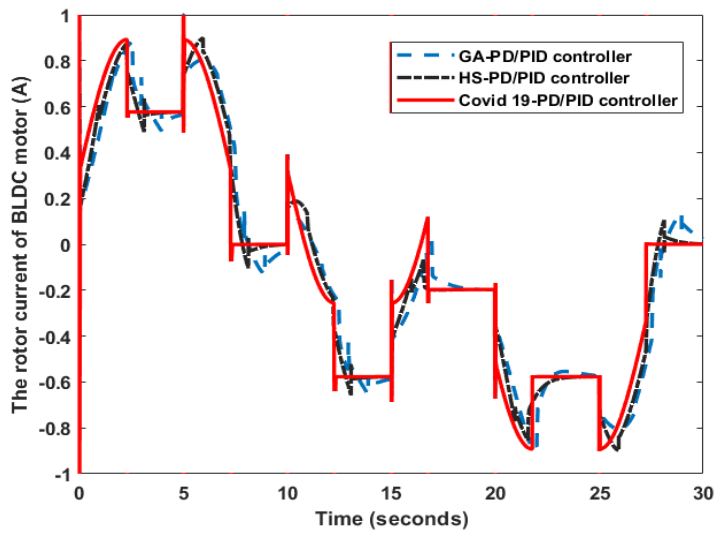

Fig. 20. The DC current of each controller at variable position command.

\section{Conclusion}

A new covid-19 optimization algorithm had been used to find the optimal values of the $\mathrm{PD} / \mathrm{PID}$ cascaded controller for robot arm driven by brushless DC (BLDC) motor. The controller objective is to track a preselected position command with satisfying accuracy all time regardless of load disturbance and parameter variations. This research, mimicking how the covid-19 infects and spreads healthy people (controller parameters). The covid-19 has two major advantages compared to other similar strategies. First, the covid-19 parameters are already determined based on disease statistics to avoid designers from selecting them with arbitrary values. Second, the approach has the capability to execute the task after several iterations where the infected population initially grows at an exponential rate. The proposed covid-19 algorithm was examined with wellrecognized optimization techniques such as the genetic algorithm (GA) and Harmony Search (HS) optimization. The desired rise time, the desired settling time, the desired overshoot, and the desired steady-state error can be concluded into a multi-objective function. In the first test, a step position reference had been subjected. In the second test, the continuous change in position reference had been subjected to the robot arm. The results provide that the covid19 based PD/PID controller has the best dynamic response among other techniques. In addition, the covid-19 based PID controller can follow accurately the position command compared to other techniques.

\section{References:}

[1] M. P. Maharajan and S. A. E. Xavier, "Design of Speed Control and Reduction of Torque Ripple Factor in BLdc Motor Using Spider Based Controller," IEEE Trans. Power Electron., vol. 34, no. 8, pp. 7826-7837, 2019, doi: 10.1109/TPEL.2018.2880916.

[2] M. A. Shamseldin, M. A. Eissa, and A. A. Elsamahy, "A Modified Model Reference Adaptive Controller for Brushless DC Motor," 17th Int. Middle East Power Syst. Conf. Mansoura Univ. December 15-17, 2015, 2015.

[3] M. Shamseldin, M. A. Ghany, and Y. Hendawey, "Optimal Nonlinear PID Speed Control Based on Harmony Search for An Electric Vehicle Optimal Nonlinear PID Speed Control Based on Harmony Search for An Electric," Futur. Eng. J., vol. 2, no. 1, 2021.

[4] B. Algorithms, "Optimization of PID Controller for Brushless DC Motor by using Bio-inspired Algorithms," Res. J. Appl. Sci. Eng. Technol., vol. 7, no. 7, pp. 1302-1308, 2014.

[5] M. A. Shamseldin, M. A. Eissa, and A. A. Elsamahy, "Practical Implementation of GABased PID Controller for Brushless DC Motor," in 17th International Middle East Power System Conference (MEPCON'15) Mansoura University,Egypt, December 15-17 ,2015, 2015.

[6] A. I. Technology, "THE DESIGN OF THE HYBRID PID-ANFIS CONTROLLER FOR SPEED CONTROL OF BRUSHLESS DC MOTOR," J. Theor. Appl. Inf. Technol., vol. 71, no. 3, pp. 367-376, 2015.

[7] S. Wen, T. Wang, Z. Ma, and X. Li, "Dynamics Modeling and Fuzzy PD Control of Humanoid Arm," in Proceedings of the 36th Chinese Control Conference, 2017, no. 3, pp. 616-621.

[8] L. Setlak and R. Kowalik, "Control system of the multi-rotor in flight in the presence of strong wind," WSEAS Trans. Syst. Control, vol. 14, pp. 437-444, 2019.

[9] M. A. Shamseldin, M. Sallam, A. M. Bassiuny, and A. M. Abdel Ghany, "LabVIEW implementation of an enhanced nonlinear PID controller based on harmony search for onestage servomechanism system," J. Comput. Appl. Res. Mech. Eng., vol. 12, pp. 4161-4179, 2019, doi: 10.15282/jmes.12.4.2018.13.0359.

[10]W.-L. Mao and Suprapto, "Indirect fuzzy contour tracking for $\mathrm{X}-\mathrm{Y}$ PMSM actuated motion system applications," IET Electr. Power 
Appl., vol. 12, no. 1, pp. 12-24, 2018, doi: 10.1049/iet-epa.2016.0881.

[11]M. A. Shamseldin, M. Sallam, A. M. Bassiuny, and A. M. A. Ghany, "A new model reference self-tuning fractional order PD control for one stage servomechanism system," WSEAS Trans. Syst. Control, vol. 14, 2019.

[12]A. M. B. and A. M. A. G. Mohamed. A. Shamseldin, Mohamed Sallam, "Real-time implementation of an enhanced nonlinear PID controller based on harmony search for onestage servomechanism system," J. Mech. Eng. Sci., vol. 12, no. 4, pp. 4161-4179, 2018, doi: https://doi.org/10.15282/jmes.12.4.2018.13.035 9.

[13]F. Compensator, J. Shen, and C. Ye, "Precision Fuzzy Sliding-mode Tracking Control with DNLRX Model Based Friction," in 2018 SICE International Symposium on Control Systems (SICE ISCS), 2018, vol. 1, no. 2.

[14]B. Siegel, "Industrial Anomaly Detection: A Comparison of Unsupervised Neural Network Architectures," IEEE Sensors Lett., vol. 4, no. $8, \quad$ pp. 15-18, 2020, doi: 10.1109/LSENS.2020.3007880.

[15]M. A. Abdel Ghany and M. A. Shamseldin, "Parallel distribution compensation PID based on Takagi-Sugeno fuzzy model applied on Egyptian load frequency control,” Int. J. Electr. Comput. Eng., vol. 10, no. 5, pp. 5274-5287, 2020, doi: 10.11591/IJECE.V10I5.PP52745287.

[16]B. Bhushan, "Position Control of Two Link Robot System by PD \& Fuzzy Controller," pp. 2-7, 2014.

[17]A. Mukhtar, V. K. Tayal, and H. P. Singh, "PSO Optimized PID Controller Design for the Process Liquid Level Control," 2019 3rd Int. Conf. Recent Dev. Control. Autom. Power Eng. RDCAPE 2019, pp. 590-593, 2019, doi: 10.1109/RDCAPE47089.2019.8979108.

[18]S. Dewangan, "Artificial Bee Colony based FOPID for SMIB System," Int. J. Digit. Appl. Contemp. Res., vol. 5, no. 8, 2017.

[19]F. Martínez-Álvarez et al., "Coronavirus Optimization Algorithm: A Bioinspired Metaheuristic Based on the COVID-19 Propagation Model," Big Data, vol. 8, no. 4, pp. 308-322, 2020, doi: 10.1089/big.2020.0051.

[20]C.-L. Xia, Permanent Magnet Brushless DC Motor Drives and Controls. Singapore: John Wiley \& Sons Singapore Pte. Ltd., 2012.

[21]M. V Ramesh, J. Amarnath, S. Kamakshaiah, and G. S. Rao, "SPEED CONTROL OF BRUSHLESS DC MOTOR BY USING,"
ARPN J. Eng. Appl. Sci., vol. 6, no. 9, pp. 5563, 2011.

[22]M. Kumar, "Harmony Search Algorithm Optimization Technique," pp. 754-757, 5093.

[23]A. Mukhtar, V. K. Tayal, and H. P. Singh, "PSO Optimized PID Controller Design for the Process Liquid Level Control," 2019 3rd Int. Conf. Recent Dev. Control. Autom. Power Eng. RDCAPE 2019, pp. 590-593, 2019, doi: 10.1109/RDCAPE47089.2019.8979108.

[24]A. Bennaoui, S. Saadi, and A. Ameur, "Performance Comparison of MFO and PSO for Optimal Tuning the fractional order fuzzy PID Controller for A DC-DC Boost Converter," 2020 Int. Conf. Electr. Eng. ICEE 2020, 2020, doi: 10.1109/ICEE49691.2020.9249778.

\section{Creative Commons Attribution License 4.0 (Attribution 4.0 International, CC BY 4.0)}

This article is published under the terms of the Creative Commons Attribution License 4.0

https://creativecommons.org/licenses/by/4.0/deed.en US 